\title{
La Cooperativa Paulista de Teatro y la Mostra V: Hacia una liga latinoamericana de teatro
}

\section{Mario A. Rojas}

La Cooperativa Paulista de Teatro acaba de cumplir treinta años, con muchos proyectos cumplidos y otros en perspectiva. Desde su fundación en 1979 se ha convertido, en palabras del profesor Hubert Alqueres, en "um patrimonio da cultura brasileira" ( 30 anos 23). En efecto, la CPT es hoy en día una referencia nacional de organización jurídica, de producción, investigación y difusión teatral y por ser un dinámico organismo que influye en políticas municipales, estatales y federales para propulsar leyes en beneficio de las artes escénicas. Siguiendo con rigor los principios del cooperativismo, la CPT ha luchado por la dignidad del trabajador escénico, no sólo a través del diálogo y la discusión cívica, sino muy a menudo, por vía de la movilización de artistas que, en espacios públicos, defienden el derecho a la cultura. Los resultados han sido extraordinarios, como puede apreciarse en su reciente publicación con que celebra el aniversario de sus treinta años. Actualmente forman parte de esta cooperativa cerca de 4.000 técnicos y artistas del teatro. También ha establecido redes de comunicación con otros artistas de Brasil para desarrollar actividades en común, una gran tarea si se considera la magnitud continental de este país. Pero Ney Piacentini, que lidera la Cooperativa desde 2005, no se conforma con esta proyección nacional. Su objetivo es más ambicioso: crear una red latinoamericana que asocie a artistas del teatro de toda América Latina. Ya hay señales claras orientadas en esta dirección. En la Mostra V se invitó a Guillermo Heras para que diera a conocer Iberescena, una organización que financia proyectos de artistas provenientes de aquellos países que contribuyen al Fondo Intergubernamental de Apoyo a las Artes Escénicas (ver su página web: www.iberescena.org). Además la CTP se propone establecer programas con la recién creada Red Latinoamericana de Teatro y con el CECIT (Centro Latinoamericano de Creación e Investigación 
Teatral) que lleva un largo recorrido en este sentido. Se trata de un promisorio plan que ayudará al desarrollo del teatro latinoamericano, y a la creación e implantación de políticas culturales que reconozcan la importancia de las artes escénicas en la cultura nacional y regional.

En este proyecto latinoamericano, se incluyen las Mostras de Teatro Latinoamericano que, además de los espectáculos, organizan sesiones diarias donde los grupos invitados comparten sus experiencias y métodos de creación. También se edita un diario informativo con críticas, comentarios y ensayos en que colaboran importantes figuras del teatro, como sucede en las ediciones de la Mostra V con la participación del colombiano César Badillo Pérez y el chileno Guillermo Calderón, además de los críticos especialmente invitados: Jorge Louraço, José Henríquez, Teresita Galimany y Valmir Santos.

\section{Adaptaciones dialógicas entre textos}

La televisión, el cine, el teatro y los musicales nos tienen acostumbrados a las adaptaciones. El tipo de diálogo que se establece entre el texto adaptado con su original responde a muchas motivaciones sean estéticas, culturales, políticas, prácticas o comerciales. A propósito de los 500 años del descubrimiento de América, aparecieron un gran número de obras teatrales para criticar el colonialismo y sus secuelas y/o para desmantelar discursos históricos oficiales. Esta tendencia ha reaparecido hoy en día en que la mayoría de los países hispanoamericanos celebran su bicentenario como naciones independientes. Tal es el caso de Pedro de Valdivia: la Gesta Inconclusa del grupo chileno Tryo Teatro Banda. Para su puesta en escena, el grupo de tres actores se basa en las Cartas de Pedro de Valdivia, el fundador de Santiago, quien fue matado cuando intentaba incorporar tierras mapuches a la corona española. En esta adaptación los actores, aprovechando su talento artístico más allá del teatro, emplean una variedad de instrumentos, algunos autóctonos como la trutruca y el kultrún y otros mestizos o europeos como el charango, la guitarra, el clarinete y el violín que, además de avanzar y amenizar la narración de los sucesos, tienen funciones coreográficas: circundan el espacio de actuación, y son también utilizados como props para la realización de algunas escenas. Un espectáculo muy dinámico es el de estos juglares contemporáneos que, con simples elementos, se los ingenian para crear miniaturas que ilustran la toponimia chilena y les permite la escenificación de acciones bélicas de carácter épico. El público paulista captó, además, sin problemas, alusiones a otros periodos de la historia de Chile, como la dictadura de Pinochet. 


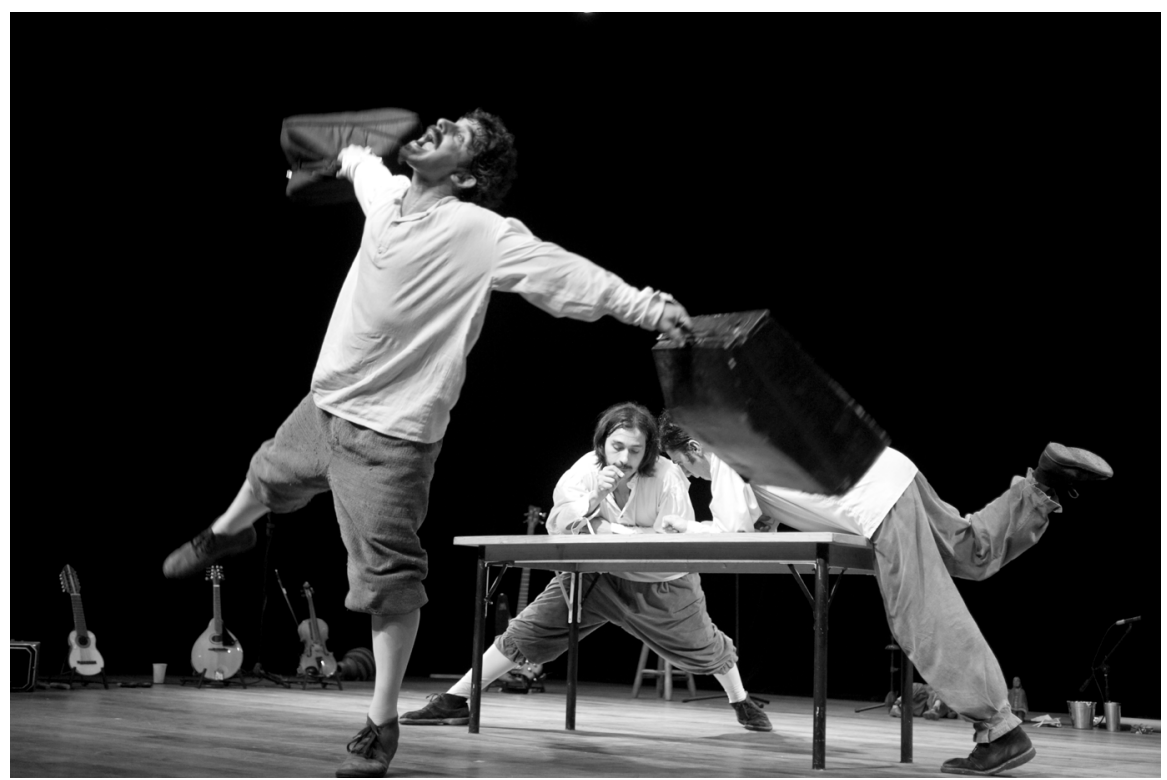

Pedro de Valdivia: la Gesta Inconclusa, Tryo Teatro Banda. Foto: Tainá Azeredo.

Los ríos profundos del peruano José María Arguedas es una de las novelas más leídas en la América Hispana, que ha llegado profundamente al lector por su lirismo y por el gran amor que el niño protagonista siente por la cultura andina. El grupo Cuatrotablas, que junto con el Yuyachkani es uno de los grupos peruanos más conocidos internacionalmente, se propuso adaptar para la escena los tres primeros capítulos de la novela a partir de la mirada, el oído, el tacto y el olfato de un joven protagonista arrobado en su contacto con los elementos ancestrales y genésicos del mundo incaico. Si el texto de Arguedas es altamente poético, no lo es menos el texto escénico del Cuatrotablas que transcodificó en metáforas sonoras, visuales y de danza el sagrado mundo incaico y nos introdujo en el conflictivo mundo interior del novelista peruano. Todo esto con una limpieza escénica excepcional que hacía relucir los mínimos elementos escénicos: libros, piedras, velas y otros objetos de valor simbólico.

La Compañía de Teatro Avante de Miami vino al festival con Aire frio, una adaptación o versión libre de la obra homónima de Virgilio Piñera realizada por Raquel Carrió del Teatro Buendía, cuya calidad como dramaturga ya habíamos apreciado en la Mostra II con Charenton, una magistral adaptación del Marat-Sade de Peter Weiss. Si bien en los casos del Tryo Teatro 
Banda y del Cuatrotablas se trataba de una adaptación transgenérica, ahora tenemos una intertextualidad con textos dramáticos, un tipo de adaptación que generalmente se hace con el fin de actualizar el texto original teniendo en mente una nueva propuesta escénica, como sucedió con Charenton. En el caso de Aire frío, Carrió modificó el texto original, agregando alusiones a otros textos o frases de Piñera, cambios que posiblemente no fueron reconocidos por el espectador paulista, pero sí pudo haber desagradado a aquel espectador que conoce bien esta obra de Piñera. Los críticos destacaron la actuación de Marilyn Romero interpretando a Luz Marina y valoraron aspectos de la puesta. Algunos espectadores leyeron en ella una velada crítica al régimen castrista, lo cual resultaría anacrónico en relación al tiempo en que Piñera escribió el texto. El hecho que el Avante esté formado por artistas cubanos residentes en Miami fue lo que, posiblemente, produjo estas suspicacias. Además, una frase dicha con vehemencia y un tono especial puede invitar al espectador a la lectura de un subtexto o, por el contrario, crear o agregar significados no pensados por el dramaturgo o el director.

\section{Cuerpo y sexo: historias de mujeres}

Estranhas Galinhas del Grupontapé de Uberlândia, Minas, del dramaturgo y director Fernando Limoeiro, se inspira en "Un señor muy viejo con unas alas enormes", de Gabriel García Márquez. No podría, sin embargo, considerarse como una adaptación del cuento del colombiano pues se toma de él sólo la imprevista llegada de un ángel, un perturbador agente de cambio de la vida cotidiana. Aquí, diferente al de García Márquez, es un ángel joven y seductor y las afectadas son tres hermanas solteras que viven encerradas en una casa patriarcal, aisladas del mundo. La acción sucede en una semana de carnaval, lo que resulta muy apropiado por el efecto de 'mundo al revés' que provoca el ángel que seduce o se deja sacudir, rompiendo la contención física y espiritual en que vivían las hermanas, maniatadas por el fanatismo religioso y la culpa. Las hermanas, al parecer, habían sido violadas por su padre, cuya figura es representada simbólicamente por una estatua de San Roque. Todo termina en una tragedia con la muerte de las tres hermanas y la huida del ángel. En la coreografía se enfatiza el encierro y el sofocamiento vital de las hermanas. En la discusión de la obra, pudimos apreciar el riguroso trabajo del grupo, de cómo cada movimiento o expresión corporal eran construidos al mínimo detalle.

La situación precaria de los inmigrantes es un tema frecuente en la dramaturgia contemporánea. El leitmotiv o eje estructural común es la 


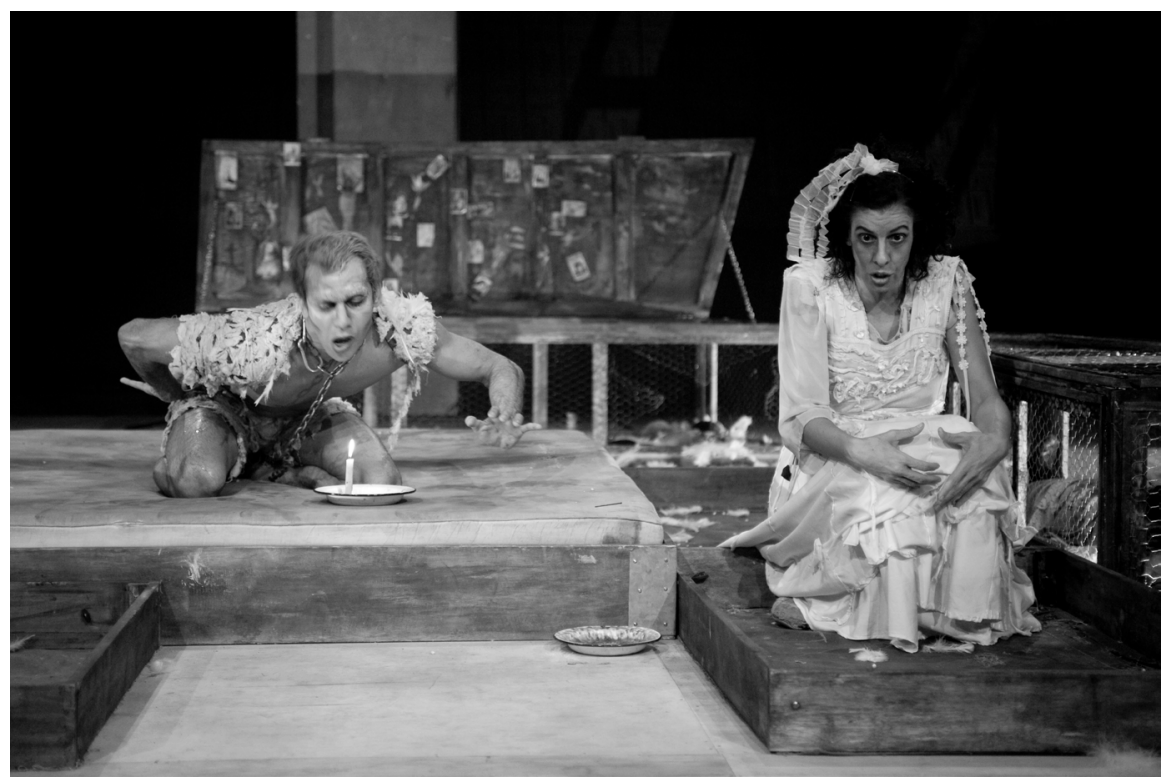

Estranhas Galinhas, Grupontapé de Uberlândia. Foto: Tainá Azeredo.

transformación de la tierra prometida en un horrible infierno, sea por la discriminación, por el abuso de los empleadores o por la incapacidad de los inmigrantes para desprenderse emocionalmente del país que dejaron atrás. En Rosita contratodo se muestra tal vez la peor cara de este fenómeno social: la esclavitud sexual. En España en el 2009, la policía registró más de 1.300 (que pueden ser más) casos de mujeres explotadas sexualmente, muchas provenientes de América Latina, especialmente de La República Dominicana y Colombia. El comercio sexual es promovido abiertamente en diarios y en internet y es controlado por empresarios del sexo (entre los tantos tipos de empresarios que abundan hoy en día). Rosita contratodo se realizó con el apoyo de Iberescena; el texto es de Diana Raznovich (argentina) y la dirección conjunta de Patricia Ariza (colombiana) y Margarita Borja (española), las tres muy conocidas por su defensa de los derechos civiles. En la obra, una periodista entrevista a Rosita, una colombiana, que llega engañada a España en busca de una vida mejor, pero es convertida en una esclava sexual. La reportera logra, con mucho esfuerzo, que la entrevista se publique en el suplemento de un diario. Esto trae como consecuencia la muerte de Rosita y la amenaza y acoso de las mafias en contra de ella y del diario. La puesta en escena tiene una estructura retro-prospectiva o circular 
que se inicia y termina con la muerte de Rosita. Una Calaca, la carnavalesca figura mexicana de la muerte, funciona como hilo conductor del espectáculo que posee las características del documental, pero que no se deja llevar por la convención realista gracias al uso de recursos escénicos como proyección de sombras, el empleo de máscaras, la danza, el cabaret y elementos circenses.

La comedia Raimunda Pinto. Sim senhor! del Grupo Harém de Teatro, de Piauí, Nordeste Brasileño, tiene en común con los dos textos anteriores que trata de historias de mujeres, pero en este caso hay un final feliz, como sucede en la comedia liviana. Es un espectáculo que se ha representado en distintos lugares desde 1992. Sólo en Piauí tuvo más de 500 representaciones, lo cual indica que es muy bien acogida por un público que se deja encantar por el tono divertido y por la singular historia de una mujer que, con pormenores inverosímiles y hasta absurdos, triunfa en la vida a pesar de sus defectos físicos y de fuerzas sociales obstructoras. También la pieza resulta atractiva por el acompañamiento en vivo de un conjunto de música popular y, sobre todo, porque es interpretada, paródica y caricaturescamente, por actores travestidos. Esta puesta se distancia también de Estranhas Galinhas y de Rosita contratado en cuanto estas poseen una estética mucho más elaborada y son realizadas por actores profesionales. Raimunda dio la impresión de un teatro hecho con garra, pero con actores aficionados.

\section{La presencia de África con la Companhia Enrique Artes (Angola)}

Una agradable sorpresa fue la inclusión en la Mostra V de Hotel Komarca de la Companhia Henrique Artes de Luanda. Mi familiaridad con el teatro de Angola y de Mozambique viene del FITEI que se realiza en Oporto. Comparado con lo visto allí, Hotel Komarca muestra un progreso en el ejercicio de un teatro de estilo realista. La acción sucede en una celda carcelaria parecida a una jaula de zoológico donde conviven hacinados siete criminales. En un doble juego de narración y mimesis, los presos relatan sus vidas. Sus historias revelan los serios problemas sociales de un país que recién se recupera de una cruenta guerra civil. Antes de un intento de escape hay una escena, la más memorable, donde un clownesco e incansable hablador (que es además el motor propulsor de la acción del espectáculo), anima la celebración de un cumpleaños que se convierte en una especie de intermezzo feliz antes del fin trágico que les espera. 


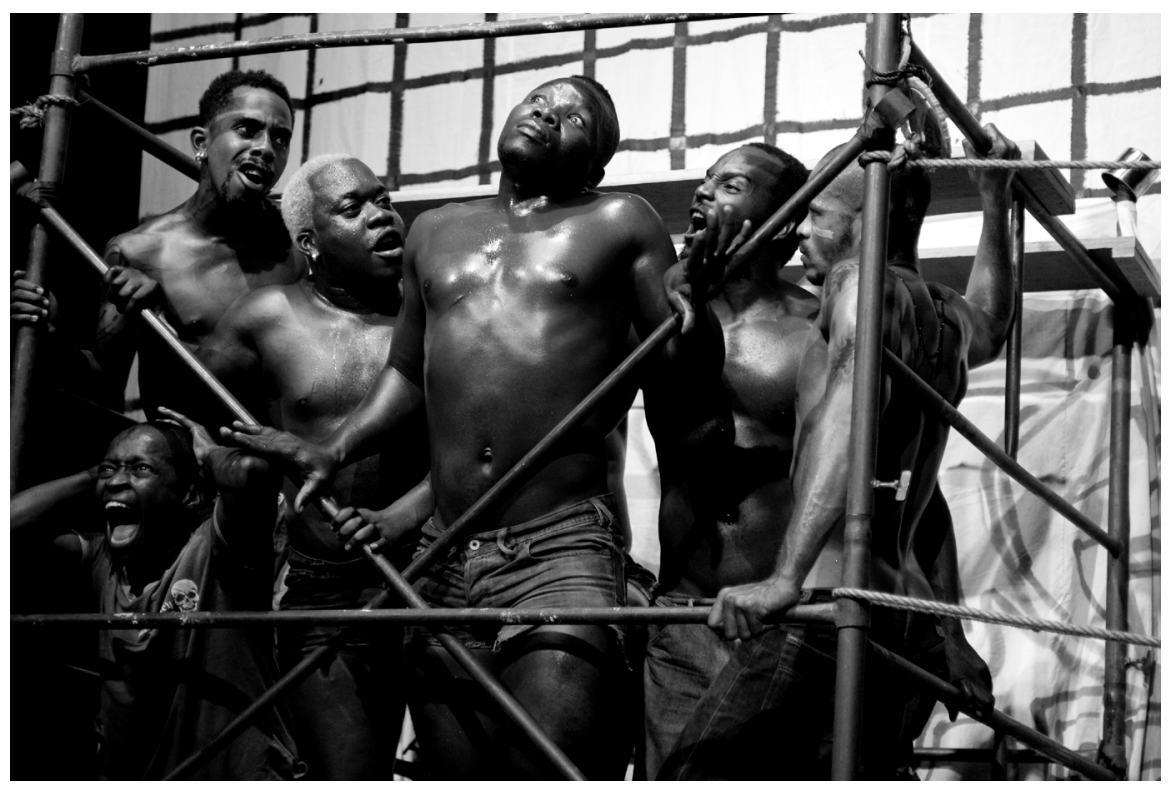

Hotel Komarca, Companhia Henrique Artes de Luanda. Foto: Tainá Azeredo.

\section{La función social y ética del artista desde un Brecht renovado}

El teatro épico brechtiano fue el paradigma más seguido en América Latina, especialmente antes de los sesenta y que luego dejó de serlo por acción de las dictaduras. Como lo ha demostrado teóricamente Fredric Jameson, el modelo brechtiano como actividad y praxis sigue vigente y esto lo han probado bien grupos como A Companhia do Latão y el Teatro de Narradores de São Paulo. Sabido es que todas las convenciones o códigos artísticos, si no se las renueva, terminan mecanizándose y dejan de lograr los efectos esperados. En Teruel y la continuidad del sueño, del Bachin Teatro de Argentina, la estética brechtiana domina en todo el espectáculo, pero se trata de un Brecht remozado. El metateatro destinado a producir precisamente el extrañamiento postulado por el maestro sirve también para cuestionar la función del narrador, esa entidad reflexiva e intermedia entre la ficción de la escena y la realidad del espectador. El narrador, a pesar de defender su estatus de pertenencia a un nivel diferente al de la ficción, pronto se deja llevar por los hechos y se zambulle como personaje de la historia: su voz se subjetiviza y relativiza pero, paradójicamente, gana en autenticidad. Teruel y la continuidad del sueño retoma una historia personal y colectiva, recuperando lo olvidado para cerrar cicatrices aun por curar. Es contada por un 
dramaturgo y director descendiente de un español republicano que murió en la Guerra Civil Española, que luchó por un sueño incumplido que reduplica muchos sueños inconclusos de nuestra América. Hubo proyecciones en un velo delante del escenario que contextualizaban acciones del pasado para relacionarlas con el presente. Teruel y la continuidad del sueño, creemos, es una pieza que cumple su objetivo, en su praxis estética, ética y social.

Cidade Desmanche de Teatro de Narradores de São Paulo nos llevó fuera del recinto del Centro Cultural, sede de la Cooperativa Paulista, a la Calle 13 de Mayo donde se encuentra el Espaço Maquinaria. El empleo de recursos cinemáticos, la utilización de espacios interiores y de la calle, su itinerancia por distintos espacios, su carácter narrativo y su auscultación o desmantelamiento (desmanche) de la ciudad paulista hicieron de este espectáculo el más interesante de ver y de seguir. Se narra la historia cruzada de un reo, que recién sale de la cárcel buscando a su antigua compañera y se encuentra perdido en una ciudad que ya no reconoce, y del Coreano, un hombre que integra una banda de falsificación de documentos y explota a bolivianos ilegales. Siete actores y dos músicos iluminan ese mundo de los socialmente excluidos y lo hacen en la cercanía física y emocional del espectador. La escenografía es una móvil que muestra la intimidad de espa-

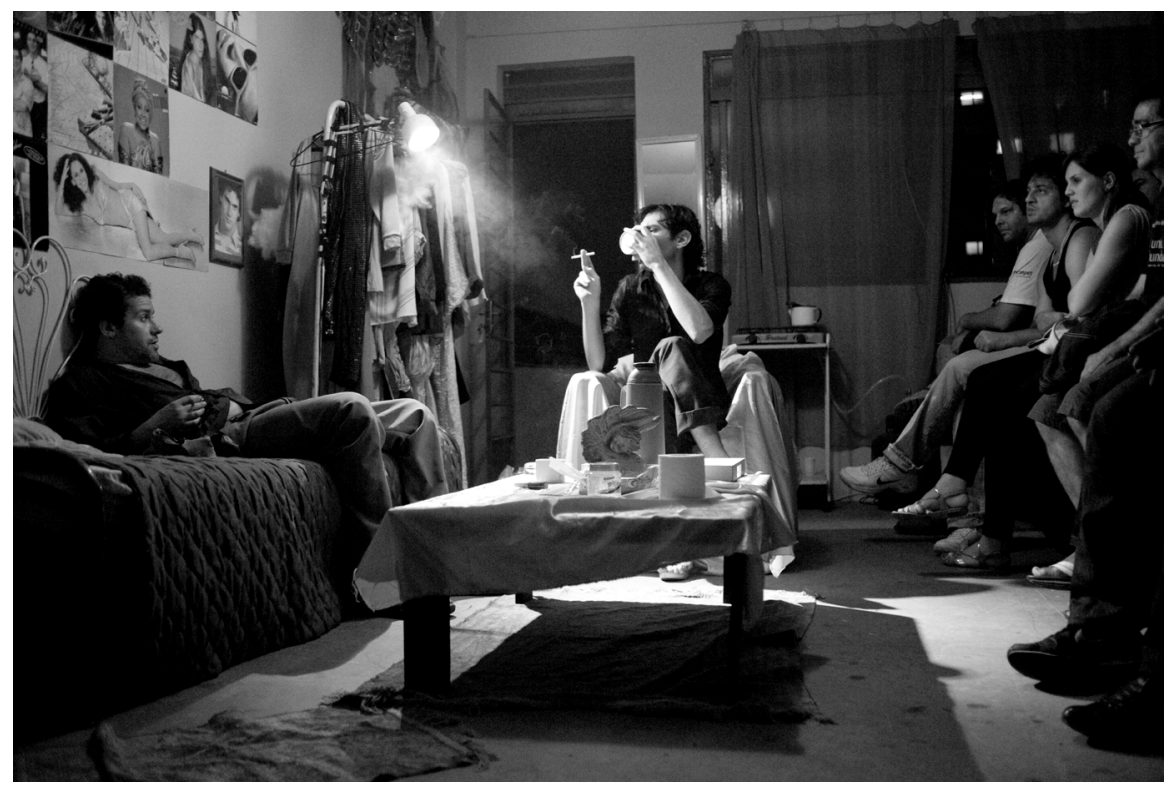

Cidade Desmanche, Teatro de Narradores de São Paulo. Foto: Tainá Azeredo. 
cios interiores que se amplían hacia fuera, por arriba a los rascacielos de la ciudad y por abajo a la animada Calle 13 de Mayo donde empieza y termina el espectáculo. En su estética, ética e ideología, este grupo de narradores (posiblemente un reflejo múltiple del narrador de Brecht) hace dialogar a Glauber Rocha y Bertolt Brecht para encontrar nuevas maneras de decir y de mostrar a la vez que interroga desmontando su mundo circundante pero también se auto-interroga en la búsqueda de nuevas expresiones artísticas.

\section{Los derechos humanos en el escenario y en la calle}

Todos los espectáculos de la Mostra, desde sus propias estéticas, manifestaron una preocupación por los derechos del hombre. Nos referiremos ahora a dos de los que lo hicieron de manera más explícita: Livres e Iguais del Teatro Sim Porque Não? de Santa Catarina y A Alegria do palhaço é ver o circo pegar fogo... del Grupo Tá na rua de Rio de Janeiro, el primero conceptuado para un espacio íntimo y el otro para el espacio abierto de la calle. Livres e Iguais es un trabajo de formas animadas, cuyo tema es la violación de los derechos humanos, particularmente el derecho negado a los seres que viven en la cara escondida de las grandes ciudades, los que no forman parte de la identidad citadina o nacional del discurso oficial, que viven de/en los

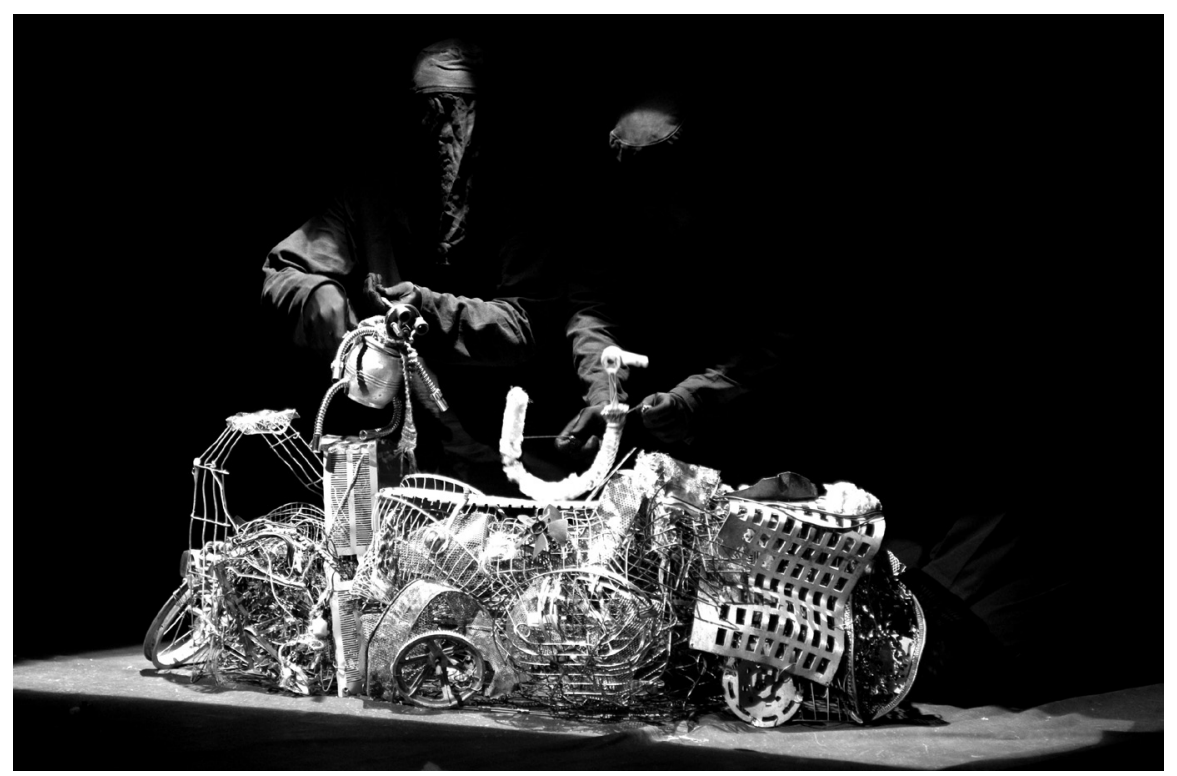

Livres e Iguais, Teatro Sim Porque Não? Foto: Tainá Azeredo. 
grandes basurales, lejos de toda posibilidad de una vida digna. Este es un tema que también había sido tratado en grupos de Mostras, como Ovo del Circo Teatro Udi Grudi. En Livres e Iguais, sin palabras ni diálogo, el tema es tratado con imágenes, sombras, música y objetos sacados de los basurales, especialmente piezas de automóviles. Muy ilustrativa fue la demostración que hizo el grupo, donde, a pesar de no haber asistido al espectáculo, pude apreciar su arte excepcional.

El Grupo Tá na rua, con su vibrante y carismático director, narrador y comentarista Amir Haddad, hizo una excepción al mostrar su trabajo de calle en un recinto semi-abierto del Centro Cultural. Todo fue alegría. Con su música y coloridos trajes y una animada participación del público, el Tá na rua conmocionó con su estilo circense y carnavalesco, pero también, al modo de Boal, lo apeló a reflexionar sobre la situación política y social de Brasil y Latinoamérica. Se trata de un teatro sin dramaturgia, que como un partido de fútbol, con un esquema previo, se va haciendo de acuerdo al dinamismo e interacción de los actores entre sí y con el público. Los espectadores reconocían y entonaban canciones de artistas brasileños y participaron en los homenajes del grupo a conocidos activistas sociales y culturales brasileños, entre ellos Augusto Boal, e identificaban figuras señeras de América Latina $\mathrm{y}$ alusiones a hechos relacionados con la historia del continente.

A Ney Piacentini, Presidente de la Cooperativa Paulista de Teatro, y a Alexandre Roit, Coordinador General de la Mostra, les agradecemos su dedicación, energía y tiempo por la realización de este importante evento.

\section{The Catholic University of America}

\section{Referencias}

30 anos da Cooperativa Paulista de Teatro 1979-2002. Ed. Alexandre Mate. São Paulo: Compañía Paulista de Teatro, 2009.

Latino-americano. Diario de la Mostra V de Teatro Latino-americano, São Paulo Cooperativa Paulista de Teatro, 2010. <www.Mostralatinoamericana.com.br $>$ 